\title{
REACTION OF CREDIT DEFAULT SWAP SPREADS TO RATING ANNOUNCEMENTS: AN EVENT STUDY FOR TURKEY
}

\section{DOI: 10.17261/Pressacademia.2015414368}

\author{
Oner Kaya Emine', Kaya Bekir², Yalciner Kursat ${ }^{3}$ \\ 'Gazi University. emineoner@gazi.edu.tr \\ 2 Gazi University. bekirkaya@gazi.edu.tr \\ ${ }^{3}$ Gazi University. yalciner@gazi.edu.tr
}

\section{Keywords \\ Credit worthiness, \\ Credit default swap spreads, sovereign credit rating announcements, event study, Turkey.}

JEL Classification G14, G24, G30

\begin{abstract}
In this study, the effect of announcements, which were made by Standard \& Poor's, Moody's and Fitch related to Turkey's sovereign credit ratings, on CDS spreads in the period between 31.10.2001 and 09.03.2015 was examined with the event study method. As a result of the conducted analysis, it has been determined that announcements made on upgrade of credit ratings or upward revisions in the sovereign's credit outlook did not lead to a significant differentiation in the 14-day period which surrounds the announcement date. On the other hand, it has been determined that announcements made on downgrade of credit ratings or downward revisions in the sovereign's credit outlook led to a significant differentiation in the 7-day period preceding the announcement and in the 7-day period following the announcement. It was determined that CDS spreads showed an abnormal increase in the 7-day period preceding the date on which the downgrade of credit ratings or downward revisions in the sovereign's credit outlook in question were announced and showed an abnormal decrease in the 7-day period which follows the announcement.
\end{abstract}

\section{DERECELENDIRME DUYURULARINA KREDI TEMERRÜT SWAP PRIMLERININ TEPKISI: TÜRKIYE IÇIN BIR OLAY ANALIZi ${ }^{1}$}

\section{Anahtar Kelimeler}

Kredi değerliliği, kredi temerrüt swap primleri, derecelendirme duyuruları, olay analizi, Türkiye.

JEL Sınıflandırması G14, G24, G30

\section{ÖZET}

Bu çalışmada, 31.10.2001 ile 09.03.2015 tarihleri arasındaki dönemde, Standard \& Poor's, Moody's ve Fitch tarafından Türkiye'nin derecelendirme notuna ilişkin yapılan duyuruların CDS primleri üzerindeki etkisi, olay analizi yöntemiyle incelenmiştir. Yapılan analiz neticesinde, derecelendirme notu ya da görünüm yükselişine ilişkin duyuruların, duyuru tarihini çevreleyen 14 günlük dönemde, CDS primleri üzerinde anlamlı bir farklılaşmaya neden olmadığı tespit edilmiştir. Öte yandan, derecelendirme notu ya da görünüm düşüşüne ilişkin duyuruların ise, CDS primleri üzerinde, duyurunun gerçekleştiği tarih öncesindeki 7 günlük ve tarih sonrasındaki 7 günlük dönemde anlamlı bir farklılaşmaya neden olduğu belirlenmiştir. Söz konusu not ya da görünüm düşüşü duyurularının açıklandığı tarihten önceki 7 günlük dönemde CDS primlerinin anormal bir artış gösterdiği, sonraki 7 günlük dönemde ise anormal bir azalış gösterdiği belirlenmiştir.

\footnotetext{
${ }^{1}$ Bu çalışma Hitit Üniversitesi tarafından 21 - 24 Ekim 2015'de Çorum'da gerçekleştirilen 19. Ulusal Finans Sempozyumunda bildiri olarak sunulmıştur.
} 


\section{GíRiş}

Ülkelerin kredi değerliliği ile ilgili göstergelerden biri olan derecelendirme notları, derecelendirme kuruluşlarının metodolojileri çerçevesinde, harf ya da rakam sistemine dayandırılarak oluşturulmaktadır. Derecelendirme notları, bir ülkenin finansal yükümlülüklerini tam ve zamanında yerine getirme düzeyinin belirlenmesine yönelik olarak derecelendirme kuruluşlarının görüşlerini ifade etmektedir (S\&P, 22.06.2015). Derecelendirme notları, derecelendirme kuruluşu tarafından oluşturulan bir takvim çerçevesinde duyurulmaktadır. Verilen notlar derecelendirme kuruluşlarınca yakından takip edilerek, gerektiğinde not artışı veya not düşüşü olarak değiştirilebilmekte ya da mevcut not teyit edilebilmektedir.

Kredi değerliliğine ilişkin bir diğer gösterge ise, kredi temerrüt swap (CDS) primleridir. CDS, yatırımcıların kredi olayı olarak ifade edilen durumlarda (temerrüt, iflas, batma, kredi notundaki düşüş) ortaya çıkan kayıplarının transfer edilmesi amacıyla kullanılan bir sözleşmedir (Kiff ve Morrow, 2000). CDS primleri ise, kredi değerliliğinin takip edilmesini sağlayan bir göstergedir. Derecelendirme notları ile karşılaştırıldığında CDS primlerine ilişkin veriler anlık olarak takip edilebilmektedir.

Derecelendirme kuruluşlarınca verilen derecelendirme notlarında ortaya çıkan değişimler finansal piyasalar tarafından yakından takip edilmektedir. Araştırmacılar da, bu alanda gerçekleştirdikleri çalışmalarla derecelendirme notu duyurularının finansal piyasalar üzerindeki etkisini tespit etmeye çalışmaktadır. Bu konuda yapılan çalışmalar daha çok derecelendirme duyurularının, hisse senedi, tahvil ve CDS piyasaları ile ilişkisinin belirlenmesi üzerine yoğunlaşmaktadır.

Bu çalışmada ise, Standard \& Poor's (S\&P), Moody's ve Fitch tarafından Türkiye'nin derecelendirme notuna ilişkin yapılan duyurulara, CDS primlerinin tepkisinin belirlenmesi amaçlanmaktadır. Böylelikle CDS primlerinin, derecelendirme duyurularından önceki dönemlerde gösterdiği değişim incelenerek, derecelendirme duyurularının öngörülmesine ilişkin bir nitelik taşıyıp taşımadıklarının belirlenmesi de mümkün olabilecektir. Bu doğrultuda çalışma beş bölümden oluşmaktadır. Girişin ardından çalışmanın ikinci kısmında literatür taramasına yer verilmektedir. Çalışmada kullanılan veri setine, değişkenlere ve yönteme ilişkin açıklamalar üçüncü kısımda yer almaktadır. Analiz bulguları dördüncü kısımda ele alınmakta ve son kısımda da elde edilen sonuçlar yorumlanmaktadır.

\section{LITERATÜR TARAMASI}

Derecelendirme duyurularının finansal piyasalar üzerindeki etkisinin belirlenmesi 2000'li yıllardan sonra araştırmacıların dikkatini çeken bir konu haline gelmiştir. Daha önce de ifade edildiği üzere, bu konuda yapılan çalışmaların, derecelendirme notu duyurularının hisse senedi, tahvil ve CDS piyasaları üzerindeki etkisinin belirlenmesi üzerine yoğunlaştığı görülmektedir. Derecelendirme notu duyurularının tahvil piyasaları üzerindeki etkisini tespit etmeye yönelik olarak yapılan çalışmalar arasında Vu, Alsakka ve Gwilym (2015) ile Böninghausen ve Zabel (2015); hisse senedi piyasaları üzerindeki etkisini tespit etmeye yönelik çalışmalar arasında Li, Shin ve Moore (2006), Bissoondoyal-Bheenick ve Brooks (2014) ile Abad ve Robles (2014); hem hisse senedi hem de tahvil piyasaları üzerindeki 
etkisini tespit etmeye yönelik çalışmalar arasında Christopher, Kimb ve Wu (2012), Afik, Feinstein ve Galil (2014) ile Afonsoa, Gomes ve Taamouti (2014); CDS piyasaları üzerindeki etkisini tespit etmeye yönelik çalışmalar arasında Micu, Remolona ve Wooldridge (2004), Hull, Predescu ve White (2004), Lehnert ve Neske (2006), Micu, Remolona ve Wooldridge (2006), Ismailescu ve Kazemi (2010), Finnerty, Miller ve Chen (2013), Blau ve Roseman (2014), Wang, Svec ve Peat (2014) ile Wengner, Burghof ve Schneider (2015); hem hisse senedi hem de CDS piyasaları üzerindeki etkisini tespit etmeye yönelik çalışmalar arasında Norden ve Weber (2004); hem tahvil hem de CDS piyasaları üzerindeki etkisini tespit etmeye yönelik çalışmalar arasında ise, Afonso, Furceri ve Gomes (2012) yer almaktadır. Bu çalışmada, Türkiye'nin derecelendirme notuna ilişkin yapılan duyurulara, CDS primlerinin tepkisinin belirlenmesi amaçlandığından, bu kısımda, derecelendirme notu duyurularının CDS piyasaları üzerindeki etkisini tespit etmeye yönelik olarak yapılmış önceki çalışmalar incelenmektedir.

Micu, Remolona ve Wooldridge (2004) tarafından yapılan çalışmada derecelendirme duyurularının CDS piyasasındaki etkisi incelenmiştir. 1 Ocak 2001 ile 31 Aralık 2003 tarihleri arasındaki dönemin incelendiği çalışmada 694 referans varlı̆̆a ait günlük CDS verisi Londra tabanlı bir kredi türev veri sağlayııından temin edilmiş olup, derecelendirme verileri Moody's ve S\&P'den sağlanmıştır. Yapılan analizler neticesinde negatif derecelendirme değişimlerinin CDS primleri üzerinde oldukça yüksek bir etkisi olduğu tespit edilmiştir. Bu etki kendini en çok negatif gözden geçirme ve derecelendirme notu düşüşlerinde göstermektedir. Görünüm değişimlerinde ise önemli bir etki saptanmamıştır.

Hull, Predescu ve White (2004) tarafından yapılan çalışmada, kredi temerrüt swap piyasası ve derecelendirme duyuruları arasındaki ilişkiyi tespit etmek amacıyla iki tür analiz gerçekleştirilmiştir. Çalışmada, CDS veri seti 5 Ocak 1998 ile 24 Mayıs 2002 tarihleri arasındaki dönemi kapsamakta ve 233.620 adet CDS fiyatlamasını içermektedir. Gerçekleştirilen birinci analizde derecelendirme duyurularına bağlı olarak CDS primlerindeki değişim incelenmiştir. Elde edilen sonuçlara göre not düşüşü için gözden geçirmeler önemli bilgiler içerirken, not düşüşleri ve negatif görünüm değişimleri önemli bilgiler içermemektedir. Yapılan ikinci analizde, CDS primlerine bağlı olarak derecelendirme notu değişiklikleri incelenmiştir. Elde edilen sonuçlara göre, negatif not değişimlerinin gerçekleşme olasılı̆̆ının tahmininde CDS primlerinin faydalı bilgiler sağladığı tespit edilmiştir. Ayrıca pozitif not değişimleri için elde edilen sonuçların, negatif not değişimleri için elde edilen sonuçlara göre daha az anlamlı olduğu sonucuna ulaşılmıştır. Ancak bu hususun örneklemdeki pozitif not değişimlerinin sayısının çok daha az olmasının bir sonucu olabileceği de ifade edilmektedir.

Norden ve Weber (2004), 2000-2002 yılları arasındaki dönemde, hisse senedi ve CDS piyasasının derecelendirme kuruluşları tarafından yapılan derecelendirme notu duyurularına tepkisini incelemiştir. Olay analizi yönteminin kullanıldığı çalışmada, anormal getiriler ve düzeltilmiş CDS primi verileri üzerinde derecelendirme duyurularını önemli bir etkisi olup olmadığı araştırılmışır. Araştırma neticesinde, her iki piyasanın yalnızca not düşüşlerine değil, not düşüşü için gözden geçirmelere de tepki verdiği tespit edilmiştir. Farklı derecelendirme duyuruları birleştirilerek yapılan analizde, S\&P ve Moody's'in not düşüşü için gözden geçirme duyurularının her iki piyasa üzerinde daha fazla etkisi olduğu belirlenmiştir. 
Lehnert ve Neske (2006) tarafından yapılan çalışmada, J.P. Morgan TRAC-X Europe endeksindeki tüm referans varlıklar için, derecelendirme duyurularına bağlı olarak kredi temerrüt swap primlerindeki değişiklikler incelenmiştir. TRAC-X şirketlerinin günlük CDS verilerinin ve Moody's tarafından yayımlanan derecelendirme duyurularının kullanıldığı araştırma, Ağustos 2000 ile Ağustos 2003 arasındaki dönemi kapsamaktadır ve seçilen üç yıllık dönemde 188 derecelendirme duyurusu gözlenmiştir. Araştırma neticesinde, daha önce yapılan çalışmalardan farklı olarak, fiili not düşüşlerinin önemli bilgi içerdiği, farkı derecelendirme duyurularının piyasa tarafından öngörülemediği, pozitif ya da durağan görünüm raporlarının duyuru sonrası CDS primleri üzerinde önemli bir etkisi olduğu ve negatif görünüm raporları ile not düşüşlerinin piyasa tarafından birbirinden bağımsız olaylar olarak kabul edildiği tespitlerine ulaşılmıştır. Çalışmada ayrıca söz konusu farklılığın kısmen kredi temerrüt swapları için Avrupa piyasasının göreceli olarak genç olmasından kaynaklanmış olabileceği de ifade edilmektedir.

Micu, Remolona ve Wooldridge (2006) daha önce yaptıkları çalışmayı geliştirmek suretiyle 1 Ocak 2001 ile 31 Mart 2005 tarihleri arasındaki dönemde yaklaşık 800 referans varlığa ait CDS primi verisi ile 6.000 'den fazla derecelendirme duyurusuna ait veriyi kullanarak derecelendirme duyurularının CDS primleri üzerindeki etkisini incelemiştir. Yapılan analiz sonucunda, pozitif ya da negatif olması fark etmeksizin görünüm, gözden geçirme ve derecelendirme notu değişimlerinin, başka bir ifadeyle her tür derecelendirme duyurusunun CDS fiyatları üzerinde anlamlı bir etkiye sahip olduğu tespit edilmiştir. Bu etki en çok gözden geçirmeler için belirgin olsa da, görünüm ve derecelendirme notu değişiklikleri için de ihmal edilemeyecek düzeydedir.

Ismailescu ve Kazemi (2010) çalışmalarında kredi derecelendirme duyurularının, duyurunun gerçekleştiği ülkenin CDS primi üzerindeki etkisini ve bu duyurunun diğer gelişmekte olan ekonomilerin CDS primlerine yayılma düzeyini incelemiştir. Bu doğrultuda çalışmada 2001-2008 yılları arasındaki S\&P kredi derecelendirme notu ve kredi görünüm duyurularına CDS piyasalarının nasıl tepki verdiğinin tespit edilmesi amacıyla standart olay analizi yöntemi kullanıımışır. Araştırma neticesinde, pozitif duyuruların, CDS piyasaları üzerinde duyurunun gerçekleştiği 2 günlük süre zarfında daha fazla etkisi olduğu ve bu etkinin diğer gelişmekte olan ülkelere de yayılma özelliği gösterdiği belirlenmiştir. Diğer yandan, CDS piyasalarının negatif duyuruları öngörebildiği ve CDS primlerindeki önceki değişimlerin negatif bir duyurunun gerçekleşme olasılığını tahmin etmek için kullanılabileceği tespit edilmiştir.

Finnerty, Miller ve Chen (2013), 2 Ocak 2001 ile 31 Mayıs 2009 tarihleri arasındaki dönemi kapsayan, CDS ve kredi derecelendirme notlarına dayalı geniş bir veri seti kullanarak gerçekleştirdikleri çalışmalarında, kredi derecelendirme duyurularının CDS primleri üzerindeki etkisini ve CDS primleri ile prim değişimlerinin, olumlu ya da olumsuz derecelendirme duyurularını öngörme yeteneğini incelemişlerdir. Elde edilen sonuçlara göre, derecelendirme notu düşüşleri kadar öngörülemiyor olsalar da, işletmelerin derecelendirme notu yükselişlerinin CDS primleri üzerinde önemli bir etkisi olduğu belirlenmiştir. Not görünüm ve gözden geçirme duyurularının, önceki kredi derecelendirme olaylarının kontrol edilmesinin ardından, pozitif not görünüm ve gözden geçirme duyurularının yapıldığı tarihlerde, anlamlı kümülatif anormal getiriye neden olduğu belirlenmiştir. Ayrıca, yatırım yapılabilir düzeyde notu olmayanların CDS 
primlerindeki değişimin, negatif derecelendirme notu olaylarının gerçekleşme olasılığının tahminine ilişkin yararı bilgiler içerdiği tespit edilmiştir.

Blau ve Roseman (2014), çalışmalarında, 5 Ağustos 2011 tarihinde gerçekleşen ABD'nin ülke kredi derecelendirme notu düşüşünün Avrupa ülkelerinin CDS primleri üzerindeki etkisini incelemişlerdir. Araştırma neticesinde, analize konu olan not düşüşünün gerçekleştiği tarihi çevreleyen on günlük dönemde, $A B D$ 'nin CDS primleri nispeten normal düzeyinde kalırken, Avrupa CDS primlerinin dalgalanma gösterdiği tespit edilmiştir. Çalışmada, söz konusu on günlük dönemde, CDS primlerinin normal seyrinden yaklaşık olarak \%25 daha yüksek düzeye çıkmış olması, CDS piyasası tarafından, ABD not düşüşünün Avrupa ülkelerindeki temerrüt olasılığını önemli ölçüde etkilediği şeklinde algılandığı yorumu yapılmaktadır. Kişi başına gayrisafi yurt içi hasılası en düşük olan Avrupa ülkelerinin ve son dönemde notu düşürülmeyen Avrupa ülkelerinin CDS primlerinde en yüksek artışın yaşandığı gözlenmiştir. Ayrıca, Euro kullanan ülkelerde, CDS primlerinin daha yüksek düzeyde artı̧̧ gösterdiği tespit edilmiştir.

Wang, Svec ve Peat (2014) tarafından yapılan çalışmada, 3 Eylül 2004 ve 30 Haziran 2011 tarihleri arasındaki dönemde, CDS primlerindeki anormal değişiklikler ölçülerek, Avustralya kredi derecelendirme duyurularının bilgi içeriği incelenmiştir. Olay analizi yönteminin kullanıldığı çalışma neticesinde, izlem düşüşlerinin ve not artışlarının değerli bilgiler içerdiği, izlem düşüşlerine piyasanın verdiği tepkinin istatistiksel olarak anlamlı olduğu ve takip eden not düşüşlerinin öngörülebildiği tespit edilmiştir. Ayrıca, not artışlarının CDS primlerindeki küçük anormal düşüşler ile ilişkili olduğu, ancak izlem yükselişlerinin yeni bir bilgi içermediği belirlenmiştir.

Wengner, Burghof ve Schneider (2015) tarafından yapılan çalışmada, 2004-2011 yılları arasındaki dönemde, S\&P kredi derecelendirme duyurularının firmaların CDS primleri üzerindeki etkisi ile bu etkinin rakip işletmelere yayılma düzeyi incelenmiştir. Çalışmada, hem not düşüşlerinin ve hem de not yükselişlerinin, gerek not değişimine konu olan işletmelerin, gerekse rakip işletmelerin CDS primleri üzerinde, derecelendirme duyurusunun gerçekleştiği tarihte, bir etkisi olduğu tespit edilmiştir. Ayrıca not düşüşlerinin not yükselişlerine kıyasla daha tahmin edilebilir olduğu belirlenmiştir.

\section{VERI VE YÖNTEM}

Çalışmanın bu kısmında kullanılan veri setine, değişkenlere ve yönteme ilişkin açıklamalar yer almaktadır.

\subsection{Veri Kümesi ve Değişkenlerin Tanımlanması}

31.10.2001 ile 09.03.2015 tarihleri arasındaki dönemi kapsayan çalışmada, derecelendirme duyuruları ve CDS primleri olmak üzere iki farklı değişken kullanılmaktadır. Kullanılan değişkenlerden ilki, S\&P, Moody's ve Fitch Ratings tarafından Türkiye'ye verilen uzun dönem yabancı para birimi cinsi ülke derecelendirme notlarına ve not görünümlerine ilişkin duyurulardır. Analiz dönemi içerisinde S\&P tarafından yapılan 4 not yükselişi, 1 not düşüşü, 8 görünüm yükselişi ve 6 görünüm düşüşü; Moody's tarafından yapılan 5 not yükselişi, 4 görünüm yükselişi ve 2 görünüm düşüşü; Fitch tarafından yapılan 5 not yükselişi, 1 not düşüşü, 5 görünüm yükselişi ve 2 görünüm düşüşü duyurusu dikkate alınmıştır. Fakat bir sonraki kısımda da ifade edileceği üzere, çalışmada kullanılan 
yöntemin özelliği gereği söz konusu duyurulardan bazıları analiz dışında tutulmuştur. Yapılan eleme işlemi sonucu S\&P tarafından yapılan 3 not yükselişi, 1 not düşüşü, 5 görünüm yükselişi, 5 görünüm düşüşü; Moody's tarafından yapılan 2 not yükselişi, 2 görünüm yükselişi, 1 görünüm düşüşü ve Fitch tarafından yapılan 5 not yükselişi, 1 not düşüşü, 2 görünüm yükselişi ve 2 görünüm düşüşüne ilişkin duyuru analize dahil edilmiştir. Derecelendirme duyurularına ilişkin verilere ilgili kurumların web sitelerinden ve analiz dönemindeki gazete arşivlerinden ulaşılmışır.

Kullanılan değişkenlerden bir diğeri, Türkiye'nin \$ cinsinden 5 yıl vadeli CDS primleridir. Piyasada işlem gören CDS sözleşmelerinin vadeleri farklılaşmakla birlikte, 5 yıl vadeli CDS sözleşmelerinin diğer vadelerdeki sözleşmelere göre daha likit olması ve ilgili literatürde (Ismailescu ve Kazemi (2010); Finnerty, Miller ve Chen (2013); Blau ve Roseman (2014); Wang, Svec ve Peat (2014); Wengner, Burghof ve Schneider (2015)) kullanılması nedeniyle, 5 yıl vadeli CDS primleri analiz sürecine dahil edilmiştir. CDS primlerine ilişkin verilere, Bloomberg ve Datastream veri tabanlarından ulaşılmışırı.

\subsection{Yöntem}

Sürekli olarak değişim gösteren bir değişken ile daha seyrek olarak değişim gösteren bir değişkenin bir arada kullanıldığı çalışmalarda, geleneksel zaman serisi analizlerine kıyasla, olay analizi yönteminin daha uygun olduğu ifade edilmektedir (Fatum ve Hutchison, 2003: 390). Bu çalışmada kullanılan değişkenlerden CDS primleri anlık olarak değişim gösterirken, derecelendirme duyuruları daha seyrek olarak gerçekleşmektedir. Bu nedenle, bu çalışmada, olay analizi yöntemi kullanılmıştır. Olay analizi yöntemi, gerçekleşen olayların finansal piyasalardaki göstergelere etkisinin ortaya koyulması amacıyla araştırmacılar tarafından sıklıkla başvurulan yöntemler arasında yer almaktadır. Bu yöntemin uygulanma aşamaları MacKinlay (1997: 14-15) tarafından aşağıdaki şekilde ifade edilmektedir:

- Olayların tanımlanması ve olay penceresinin belirlenmesi

- Seçim ölçütlerinin belirlenmesi

- Tahmin penceresinin tanımlanması ve anormal değişimlerin ölçülmesi

- Ampirik sonuçların elde edilmesine ilişkin modelin tasarımı

Çalışmada, S\&P, Moody's ve Fitch tarafından yapılan, Türkiye'nin uzun dönem yabancı para birimi cinsi ülke derecelendirme notlarına ve not görünümlerine ilişkin duyurular olay olarak kabul edilmektedir. Bu olayların gerçekleştiği tarihler ise olay tarihleri (t)'dir. Olay penceresi, olayın CDS primleri üzerindeki etkisinin inceleneceği, söz konusu olayın gerçekleştiği tarihten önceki ve sonraki belirli bir dönemi ifade etmektedir. Olayı çevreleyen dönemin de incelenmesini sağladığı için, olay penceresi olayın gerçekleştiği süreden daha uzun bir dönemi kapsamaktadır (MacKinlay, 1997: 14). Bu çalışmada olay penceresi, olayın (derecelendirme duyurusunun) gerçekleştiği tarihi, bu tarihten önceki 7 iş gününü ve sonraki 7 iş gününü içerecek şekilde 15 günlük dönem olarak belirlenmiştir. Söz konusu dönem belirlenirken, olayların birbiri ile çakışma ihtimalinin en az düzeye indirilmesi amaçlanmıştır. Olayın etkisinin değerlendirilebilmesi için, olay penceresi olarak ifade ettiğimiz dönemde, CDS primlerindeki anormal değişimlerin ölçülmesi gerekmektedir. Bu doğrultuda öncelikle olayın etkisinin hissedilmediği bir döneme ilişkin normal değişim belirlenmelidir. Tahmin penceresi olarak ifade edilen bu dönem için 
genellikle olay penceresinden önceki bir dönem tercih edilmektedir (Mackinlay, 1997: 15). Bu çalışmada, tahmin penceresi, olay penceresinden önceki 14 günlük (iş günü) dönem olarak belirlenmiştir. Bu doğrultuda, olay analizine ilişkin oluşturulan zaman çizelgesi Şekil 1 'de gösterilmektedir.

Şekil 1: Olay Analizi Zaman Çizelgesi

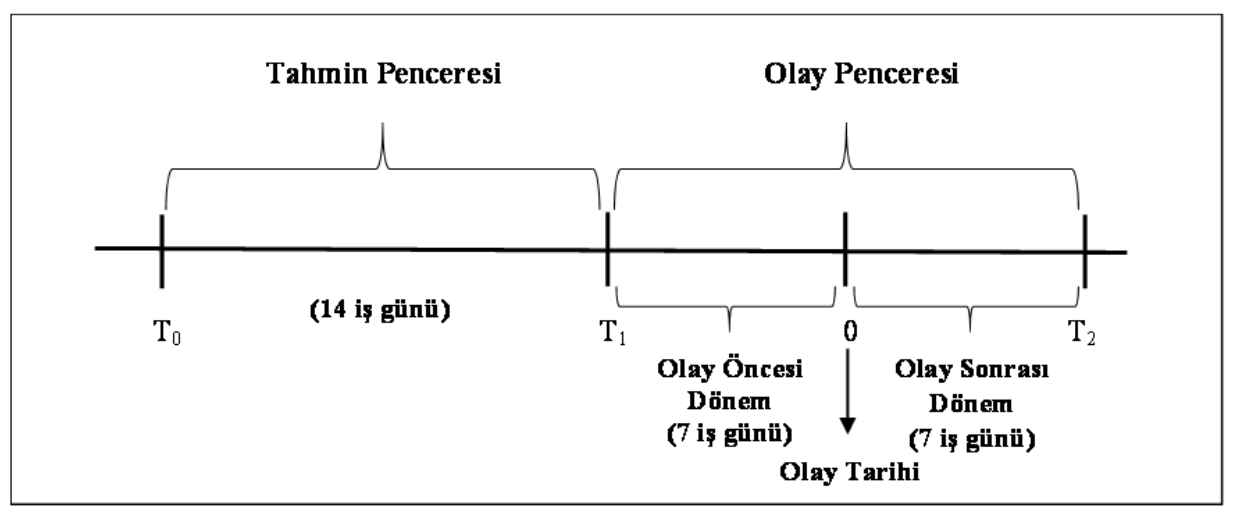

Kaynak: MacKinlay, A. C. (1997), Event Studies in Economics and Finance, Journal of Economic Literature, 35(1), p. 20 kaynağından uyarlanmıştır.

Çalışmada, S\&P, Moody's ve Fitch tarafından yapılan not ve görünüm teyitlerine ilişkin duyurular olay kapsamı dışında tutulmuştur. Ayrıca 15 günlük olay penceresi ile normal değişimlerin hesaplandığı 14 günlük tahmin penceresinde, yani toplam 29 günlük dönemde çakışan olaylar da analiz kapsamı dışında bırakılmıştır.

Derecelendirme duyurularının yapıldığı tarihler etrafında (olay öncesi ve olay sonrası dönemde) modele dahil edilen değişkenlerde ortaya çıkan anormal değişimlerin $\left(A D_{t}\right)$ hesaplanabilmesi için, öncelikle tahmin penceresindeki normal (beklenen) değişimin hesaplanması gerekmektedir. Bu amaçla kullanılan çeşitli yaklaşımlar bulunmaktadır. Ortalama getiri yaklaşımı, piyasa getirisi yaklaşımı, portföy getirisi yaklaşımı ve riske göre düzeltilmiş getiri yaklaşımı, bu yaklaşımlar arasında yer almaktadır (Henderson, 1990: 285). Bu çalışmada, normal değişimlerin belirlenmesinde, ortalama getiri yaklaşımı kullanılmıştır. Bu yaklaşıma göre öncelikle CDS primlerine ilişkin günlük değişimlerin hesaplanması gerekmektedir. Bu doğrultuda, ilgili değişkenin t zamanındaki değerinden t-1 zamanındaki değeri çıkarılarak, $\mathrm{t}$ zamanındaki günlük değişim değeri hesaplanmaktadır. Daha sonra değişkenin tahmin periyodundaki 14 günlük değişiminin aritmetik ortalaması alınıp, tahmin penceresindeki normal değişim $\left(\bar{D}_{t}\right)$ hesaplanmaktadır.

Değişkenlerin tahmin penceresindeki normal değişimlerinin tespit edilmesinin ardından, olay penceresindeki anormal değişimlerinin hesaplanması gerekmektedir. Bu amaçla, değişkenlerin olay penceresindeki gerçekleşen günlük değişimlerinden $D_{t}$, tahmin penceresindeki normal değişimlerinin çıkarılması yeterli olmaktadır (Bkz. 1 nolu denklem).

$A D_{t}=D_{t}-\bar{D}_{t}$ 
1 nolu denklemde, $A D_{t}$, $t$ gününde $C D S$ primindeki anormal değişimi; $D_{t}$, gününde $C D S$ priminde hesaplanan gerçekleşen değişimi; $\bar{D}_{t}, \mathrm{t}$ gününde $\operatorname{CDS}$ priminde beklenen (normal) değişimi ifade etmektedir.

Olay penceresindeki her bir gün için CDS primindeki anormal değişimlerin elde edilmesinin ardından, aynı nitelikteki olayların yine olay penceresindeki her bir gün için ortalama anormal değişimlerinin bulunması gerekmektedir. Bu amaçla, aynı türdeki bütün olayların t günündeki anormal değişimleri toplanarak ilgili olay sayısına bölünmüştür (Bkz. 2 nolu denklem).

$O A D_{t}=\frac{1}{N} \sum_{t=1}^{N} A D_{t}$

2 nolu denklemde, $O A D_{t}$, aynı türdeki olayların olay penceresindeki her bir gün için ortalama anormal değişimini; $\mathrm{N}$ ise aynı türdeki olay sayısını ifade etmektedir.

Değişkenlere ilişkin olay penceresindeki her bir gün için ortalama anormal değişimlerin belirlenmesinden sonra, Türkiye'nin derecelendirme notuna ilişkin yapılan duyurulara, CDS primlerinin tepkisinin belirlenmesi amacıyla, hipotez testlerinden yararlanılmaktadır. Hipotez testleri, parametrik hipotez testleri ve parametrik olmayan hipotez testleri olmak üzere ikiye ayrılmaktadır. Hipotez testlerinin, parametrik ve parametrik olmayan testler olarak ayrımında temel olan dayandığı varsayımlardır. Verilerin normal dağılıma sahip bir ana kütleden geldiği varsayımı sağlandığında, parametrik testlerin; normal dağılım varsayımı sağlanamadığında ise parametrik olmayan testlerin kullanılması gerekmektedir (Gürsakal, 2014: 151).

Verilerin normal dağııp dağılmadığının belirlenmesi amacıyla normallik testleri kullanılabilmektedir. Bu amaçla kullanılacak test türünün belirlenmesinde ise örneklem büyüklüğü önemli olmaktadır. Nitekim örneklem büyüklüğünün 50 'den küçük olması durumunda Shapiro-Wilk testi, büyük olması durumunda ise Kolmogorov-Smirnov testi kullanılmaktadır (Büyüköztürk, 2012: 42).

Çalışmada, verilerin normal dağıldığı durumlarda, parametrik testlerden eşleştirilmiş örneklemler t-testi kullanılmıştır. Eşleştirilmiş örneklemler t-testi, ilişkili iki örneklem grubunun ortalaması arasındaki farkın sıfırdan anlamlı bir şekilde farklı olup olmadığının belirlenmesi amacıyla kullanılmaktadır (Büyüköztürk, 2012: 67). Çalışmada, eşleştirilmiş örneklemler t-testiyle, CDS primlerindeki ortalama anormal değişimlerde, derecelendirme duyurusu öncesinde ve sonrasında, anlamlı bir farklılaşma olup olmadığının belirlenmesi amaçlanmaktadır.

Eşleştirilmiş verilerin farklarının normal dağıııma uygun olmadığı durumlarda ise parametrik olmayan testlerden biri olan Wilcoxon işaretli sıralar testi kullanılabilmektedir (Gürsakal, 2014: 167). Wilcoxon işaretli sıralar testi, eşleştirilmiş seriler arasındaki farkların yönü ve boyutlarını dikkate alarak iki değişkene ait dağııımların aynı olup olmadığını test etmek amacıyla kullanılmaktadır (Altunışık vd., 2007: 186). Bu doğrultuda, çalışmada normallik varsayımının sağlanamadığı durumlarda, Wilcoxon işaretli sıralar testi kullanılmıştır. Bu test ile CDS primlerinin ortalama anormal değişimlerinin olay öncesi ve 
sonrası dönemde anlamlı bir farklılaşma gösterip göstermediğinin belirlenmesi amaçlanmaktadır.

\section{ANALIZ SONUÇLARI}

CDS primlerindeki ortalama anormal değişimlerin, derecelendirme duyurusunun yapıldığı tarihten önceki ve sonraki dönemlerde karşılaştırılabilmesi için, her bir modeldeki değişkenlerin fark değerlerinin normal dağılıma uygunluğunun belirlenmesi gerekmektedir. Bu amaçla yapılan Kolmogorov-Smirnov ve Shapiro-Wilk testlerinin sonuçları Tablo 1'de yer almaktadır.

Tablo 1: Normal Dağılım Testlerinin Sonuçları

\begin{tabular}{|c|c|c|c|c|c|c|c|c|c|}
\hline \multirow{2}{*}{$\begin{array}{l}\text { Model } \\
\text { No }\end{array}$} & \multirow[b]{2}{*}{ Kuruluş } & \multirow{2}{*}{$\begin{array}{c}\text { Derecelendirme } \\
\text { Duyurusu }\end{array}$} & \multirow{2}{*}{$\begin{array}{c}\text { Duyuru } \\
\text { (Olay) } \\
\text { Sayısı }\end{array}$} & \multicolumn{3}{|c|}{ Kolmogorov-Smirnov } & \multicolumn{3}{|c|}{ Shapiro-Wilk } \\
\hline & & & & İstatistik & $\begin{array}{c}\text { Gözlem } \\
\text { Sayısı }\end{array}$ & $\begin{array}{c}p \\
\text { değeri }\end{array}$ & İstatistik & $\begin{array}{l}\text { Gözlem } \\
\text { Sayısı }\end{array}$ & $\stackrel{p}{\text { değeri }}$ \\
\hline Model 1 & \multirow{4}{*}{$S \& P$} & $\begin{array}{l}\text { Görünüm } \\
\text { Yükselişi }\end{array}$ & 5 & 0,332 & 7 & 0,019 & 0,842 & 7 & $0,105^{*}$ \\
\hline Model 2 & & $\begin{array}{l}\text { Görünüm } \\
\text { Düşüşü }\end{array}$ & 5 & 0,256 & 7 & $0,182^{*}$ & 0,879 & 7 & $0,223^{*}$ \\
\hline Model 3 & & Not Yükselişi & 3 & 0,265 & 7 & $0,148^{*}$ & 0,928 & 7 & $0,535^{*}$ \\
\hline Model 4 & & Not Düşüşü & 1 & 0,163 & 7 & $0,200^{*}$ & 0,960 & 7 & $0,815^{*}$ \\
\hline Model 5 & \multirow{3}{*}{ Moody's } & $\begin{array}{l}\text { Görünüm } \\
\text { Yükselişi }\end{array}$ & 2 & 0,209 & 7 & $0,200^{*}$ & 0,927 & 7 & $0,527^{*}$ \\
\hline Model 6 & & $\begin{array}{c}\text { Görünüm } \\
\text { Düşüşü }\end{array}$ & 1 & 0,259 & 7 & $0,172^{*}$ & 0,910 & 7 & $0,392^{*}$ \\
\hline Model 7 & & Not Yükselişi & 2 & 0,271 & 7 & $0,130^{*}$ & 0,887 & 7 & $0,257^{*}$ \\
\hline Model 8 & \multirow{4}{*}{ Fitch } & $\begin{array}{l}\text { Görünüm } \\
\text { Yükseliş̧i }\end{array}$ & 2 & 0,150 & 7 & $0,200^{*}$ & 0,979 & 7 & $0,956^{*}$ \\
\hline Model 9 & & $\begin{array}{l}\text { Görünüm } \\
\text { Düşüşü }\end{array}$ & 2 & 0,197 & 7 & $0,200^{*}$ & 0,916 & 7 & 0,440 * \\
\hline $\begin{array}{c}\text { Model } \\
10\end{array}$ & & Not Yükselişi & 5 & 0,315 & 7 & 0,034 & 0,835 & 7 & $0,089^{*}$ \\
\hline $\begin{array}{c}\text { Model } \\
11\end{array}$ & & Not Düşüşü & 1 & 0,307 & 7 & 0,045 & 0,871 & 7 & 0,190 * \\
\hline $\begin{array}{c}\text { Model } \\
12\end{array}$ & \multirow{4}{*}{$\begin{array}{l}\text { S\&P- } \\
\text { Moody's- } \\
\text { Fitch }\end{array}$} & $\begin{array}{l}\text { Görünüm } \\
\text { Yükselişi }\end{array}$ & 9 & 0,275 & 7 & $0,118^{*}$ & 0,793 & 7 & 0,035 \\
\hline $\begin{array}{c}\text { Model } \\
13\end{array}$ & & $\begin{array}{l}\text { Görünüm } \\
\text { Düşüşü }\end{array}$ & 8 & 0,325 & 7 & 0,026 & 0,810 & 7 & $0,051^{*}$ \\
\hline $\begin{array}{c}\text { Model } \\
14\end{array}$ & & Not Yükselişi & 10 & 0,247 & 7 & $0,200^{*}$ & 0,915 & 7 & $0,432^{*}$ \\
\hline $\begin{array}{c}\text { Model } \\
15\end{array}$ & & Not Düşüşü & 2 & 0,293 & 7 & 0,069 & 0,880 & 7 & $0,224^{*}$ \\
\hline
\end{tabular}

Not: * işareti serinin normal dağılıma uygun olduğunu göstermektedir.

Kaynak: Tablo, SPSS 16 programı ile elde edilen veriler kullanılarak oluşturulmuştur.

Tablo 1'de yer alan normal dağılım testlerinin sonuçları incelendiğinde, örneklem büyüklüğü 50'den küçük olduğu için, Shapiro-Wilk testi sonuçlarının dikkate alınması gerekmektedir. Analizde hesaplanan $p$ değerinin 0,05 ten büyük çıkması, bu anlamlılık düzeyinde puanların normal dağılımdan anlamlı sapma göstermediği, uygun olduğu 
şeklinde yorumlanmaktadır (Büyüköztürk, 2012: 42). Bu bağlamda CDS değişkenine ilişkin, S\&P-Moody's-Fitch görünüm yükselişi duyurularının yer aldığı modelde normal dağılım varsayımının sağlanamadığı, diğer bütün modellerde ise söz konusu varsayımın sağlandı̆̆ı görülmektedir.

Normal dağılım varsayımının sağlandığı modellere ilişkin eşleştirilmiş örneklemler t-testi sonuçları Tablo 2'de yer almaktadır.

Tablo 2: Eşleştirilmiş Örneklemler T-Testi Sonuçları

\begin{tabular}{|c|c|c|c|c|c|}
\hline Derecelendirme Duyurusu & Model No & Ortalama Farkı & Standart Sapma & T-Test & p değeri \\
\hline S\&P Görünüm Yükselişi & Model 1 & $-2,41$ & 4,59 & $-1,39$ & 0,21 \\
\hline S\&P Görünüm Düşüşü & Model 2 & 8,59 & 12,45 & 1,83 & 0,12 \\
\hline S\&P Not Yükselişi & Model 3 & $-2,61$ & 10,59 & $-0,65$ & 0,54 \\
\hline S\&P Not Düşüşü & Model 4 & 3,15 & 3,33 & 2,50 & $0,05^{* *}$ \\
\hline Moody's Görünüm Yükselişi & Model 5 & 0,71 & 9,65 & 0,20 & 0,85 \\
\hline Moody's Görünüm Düşüşü & Model 6 & $-0,50$ & 5,62 & $-0,24$ & 0,82 \\
\hline Moody's Not Yükselişi & Model 7 & $-3,01$ & 4,56 & $-1,75$ & 0,13 \\
\hline Fitch Görünüm Yükselişi & Model 8 & $-0,20$ & 4,90 & $-0,11$ & 0,92 \\
\hline Fitch Görünüm Düşüşü & Model 9 & 9,28 & 4,88 & 5,03 & $0,00^{*}$ \\
\hline Fitch Not Yükselişi & Model 10 & 3,73 & 8,12 & 1,215 & 0,27 \\
\hline Fitch Not Düşüşü & Model 11 & 111,96 & 129,76 & 2,28 & $0,06^{* * *}$ \\
\hline $\begin{array}{l}\text { S\&P-Moody's-Fitch } \\
\text { Görünüm Düşüşü }\end{array}$ & Model 13 & 7,62 & 7,41 & 2,72 & $0,04^{* *}$ \\
\hline $\begin{array}{l}\text { S\&P-Moody's-Fitch } \\
\text { Not Yükselişi }\end{array}$ & Model 14 & 0,48 & 5,83 & 0,22 & 0,84 \\
\hline $\begin{array}{l}\text { S\&P-Moody's-Fitch } \\
\text { Not Düşüşü }\end{array}$ & Model 15 & 57,56 & 64,49 & 2,36 & $0,06^{* * *}$ \\
\hline
\end{tabular}

Not: $* \% 1$ düzeyinde, $* * \% 5$ düzeyinde, $* * * \% 10$ düzeyinde istatistiki olarak anlamlı olduğunu göstermektedir. Kaynak: Tablo, SPSS 16 programı ile elde edilen veriler kullanılarak oluşturulmuştur.

Tablo 2'deki eşleştirilmiş örneklemler t-testi sonuçları değerlendirildiğinde, CDS primlerinin ortalama anormal değişimlerinin, olay öncesi ve sonrası dönemlerde, S\&P not düşüşü (Model 4), Fitch görünüm düşüşü (Model 9), Fitch not düşüşü (Model 11), S\&PMoody's-Fitch görünüm düşüşü (Model 13) ve S\&P-Moody's-Fitch not düşüşü (Model 15) duyurularının yer aldığı modellerde istatistiki olarak anlamlı bir şekilde farklılaştığı 
görülmektedir. CDS primlerindeki ortalama anormal değişimlerin olay öncesi ve olay sonrası dönemlerde farklılaştığı modellerin eşleştirilmiş örneklemler istatistikleri Tablo 3'te yer almaktadır.

Tablo 3: CDS Değişkenine iliş̧kin Seçilen Modellerin Eşleştirilmiş Örneklemler İstatistikleri

\begin{tabular}{|c|c|c|c|c|c|c|c|}
\hline \multirow[b]{2}{*}{ Model No } & \multirow[b]{2}{*}{$\begin{array}{c}\text { Derecelendirme } \\
\text { Duyurusu }\end{array}$} & \multicolumn{3}{|c|}{ Olay Öncesi Dönem } & \multicolumn{3}{|c|}{ Olay Sonrası Dönem } \\
\hline & & Ortalama & $\begin{array}{l}\text { Standart } \\
\text { Sapma }\end{array}$ & $\begin{array}{c}\text { Standart } \\
\text { Hata } \\
\text { Ortalama }\end{array}$ & Ortalama & $\begin{array}{l}\text { Standart } \\
\text { Sapma }\end{array}$ & $\begin{array}{c}\text { Standart } \\
\text { Hata } \\
\text { Ortalama }\end{array}$ \\
\hline Model 4 & $\begin{array}{l}\text { S\&P } \\
\text { Not Düşüşü }\end{array}$ & 2,88 & 4,09 & 1,54 & $-0,27$ & 2,48 & 0,94 \\
\hline Model 9 & $\begin{array}{l}\text { Fitch } \\
\text { Görünüm Düşüşü }\end{array}$ & 3,76 & 5,34 & 2,02 & $-5,52$ & 6,31 & 2,38 \\
\hline Model 11 & $\begin{array}{l}\text { Fitch } \\
\text { Not Düşüşü }\end{array}$ & 73,84 & 118,70 & 44,87 & $-38,13$ & 74,16 & 28,03 \\
\hline Model 13 & $\begin{array}{l}\text { S\&P-Moody's- } \\
\text { Fitch Görünüm } \\
\text { Düşüşü }\end{array}$ & 5,04 & 4,90 & 1,85 & $-2,58$ & 5,50 & 2,08 \\
\hline Model 15 & $\begin{array}{l}\text { S\&P-Moody's- } \\
\text { Fitch Not Düşüşü }\end{array}$ & 38,36 & 59,05 & 22,32 & $-19,20$ & 37,05 & 14,00 \\
\hline
\end{tabular}

Kaynak: Tablo, SPSS 16 programı ile elde edilen veriler kullanılarak oluşturulmuştur.

Tablo 3'te yer alan modellerde, olay öncesi dönemde CDS primlerinin ortalama anormal değişiminin pozitif yönde, olay sonrası dönemde ise negatif yönde gerçekleştiği görülmektedir. Buna bağlı olarak, derecelendirme duyurularının (not veya görünüm düşüşü) CDS primleri üzerindeki etkisinin olay öncesi dönemde ortaya çıktığı, olay sonrası dönemde ise ortadan kalktığı ifade edilebilir.

Normal dağılım varsayımını sağlayamayan S\&P-Moody's-Fitch Görünüm Yükselişi modeli (Model 12) için ise, Wilcoxon işaretli sıralar testi yapılmış olup, söz konusu test sonuçlarına Tablo 4'te yer verilmektedir.

Tablo 4: S\&P-Moody’s-Fitch Görünüm Yükselişi Modeli Wilcoxon İşaretli Sıralar Testi Sonuçları

\begin{tabular}{|cc|c|c|c|c|}
\hline & $\mathbf{N}$ & $\begin{array}{c}\text { Sıra } \\
\text { Ortalaması }\end{array}$ & $\begin{array}{c}\text { Sıra } \\
\text { Toplamı }\end{array}$ & Z-Test & p değeri \\
\hline CDS_SONRA - CDS_ÖNCE & Negatif Sıra & $4^{\mathrm{a}}$ & 2,75 & 11,00 &,$- 507^{\mathrm{d}}$ \\
& Pozitif Sıra & $3^{\mathrm{b}}$ & 5,67 & 17,00 & \\
& Eşit & $0^{\mathrm{c}}$ & & & \\
& Toplam & 7 & & \\
\hline
\end{tabular}

${ }^{a}$ CDS_SONRA $<$ CDS_ONCE 


\footnotetext{
${ }^{\mathrm{b}}$ CDS_SONRA > CDS_ONCE

${ }^{\mathrm{C}}$ CDS_SONRA $=$ CDS_ONCE

${ }^{\mathrm{d}}$ Negatif sıralar temeline dayalı

Not: * \%1 düzeyinde, $* * \% 5$ düzeyinde, $* * * \% 10$ düzeyinde istatistiki olarak anlamlı olduğunu göstermektedir.

Kaynak: Tablo, SPSS 16 programı ile elde edilen veriler kullanılarak oluşturulmuştur.
}

Tablo 4'te yer alan sonuçlar incelendiğinde, S\&P-Moody's-Fitch görünüm yükselişi duyurularının yer aldığı modelde, CDS primlerinin olay öncesi ve olay sonrası dönem ortalama anormal değişimlerinin, istatistiki olarak anlamlı bir şekilde farklılaşmadı̆̆ı görülmektedir.

\section{SONUÇ}

S\&P, Moody's ve Fitch derecelendirme kuruluşlarınca Türkiye için yapılan not ve görünüm değişikliklerinin olay olarak kabul edildiği ve CDS primlerinin söz konusu olaylara, olay öncesi ve olay sonrası dönemlerde verdiği tepkinin olay analizi metodu ile araştırıldığı bu çalışmada, 31.10.2001 ile 09.03.2015 tarihleri arasındaki 3484 CDS verisi kullanılmıştır. S\&P, Moody's ve Fitch tarafından Türkiye' nin derecelendirme notuna ilişkin yapılan toplam 9 görünüm yükselişi, 8 görünüm düşüşü, 10 not yükselişi ve 2 not düşüşü duyurusu analize dahil edilmiş olup, derecelendirme duyuruları öncesindeki ve sonrasındaki dönemlerde CDS primlerindeki değişimi incelemek üzere 15 ayrı model oluşturulmuştur.

Çalışmada kullanılan verilerin normal dağılım varsayımını sağlayıp sağlamadığının belirlenmesi amacıyla Kolmogorov-Smirnov ve Shapiro-Wilk testleri kullanılmıştır. Normal dağılım varsayımını sağlayan modellere eşleştirilmiş örneklemler t-testi, sağlayamayan modellere ise Wilcoxon işaretli sıralar testi uygulanmıştır.

Yapılan analiz sonuçları, not ve görünüm yükselişi duyurularının yapıldığı tarihler öncesindeki ve sonrasındaki dönemlerde, CDS primleri ortalama anormal değişimlerinin istatistiki olarak anlamlı bir şekilde farklılaşmadığını göstermektedir. Not ve görünüm yükselişine ilişkin duyurular ayrı ayrı olmak üzere, söz konusu duyurular kuruluş bazında ele alındığında ya da tüm kuruluşlar bir arada dikkate alınarak modellendiğinde farklı bir sonuç ortaya çıkmamıştır. Bu durum, not ve görünüm yükselişlerine ilişkin duyuruların, Türkiye'nin CDS primleri üzerinde istatistiki olarak anlamlı bir etkiye sahip olmadı̆̆ı şeklinde yorumlanabilir.

Not ve görünüm düşüşlerine ilişkin sonuçlar ise, model bazında farklılaşmaktadır. Not düşüşlerine ilişkin duyuruların ayrı ayrı yer aldığı modellerde (Model 4 ve Model 11) ve bir arada dikkate alındığı modelde (Model 15), CDS primi ortalama anormal değişimlerinin duyuru tarihinden önceki ve sonraki dönemlerde anlamlı bir şekilde farklılaştığı tespit edilmiştir. Benzer sonuçlar, sadece Fitch görünüm düşüşü duyurularının dikkate alındığı modelde (Model 9) ve tüm kuruluşların görünüm düşüşü duyuruları bir arada modellendiğinde (Model 13) de elde edilmiştir. Bu doğrultuda, söz konusu not ve görünüm düşüşü duyuruları için, duyuru tarihinden önceki dönemde CDS primlerinin anormal bir artış gösterdiğini, duyuru tarihinden sonraki dönemde ise, anormal bir azalış gösterdiğini ifade etmek mümkündür. Bu sonuç, önceden fiyatlanan duruma verilen tepkinin zamanla azalması ile açıklanabilir. Ayrıca, CDS primlerinin gösterdiği değişimin, not ve görünüm 
düşüşlerinin gerçekleşmesinin tahminine ilişkin faydalı bilgiler sağladığı da ifade edilebilir. Not ve görünüm düşüşü duyurularına ilişkin elde edilen bu sonuçlar, Micu, Remolona ve Wooldridge (2004), Norden ve Weber (2004), Ismailescu ve Kazemi (2010) ile Wengner, Burghof ve Schneider (2015) tarafından yapılan çalışmalardaki sonuçları da destekler niteliktedir.

Çalışmada, S\&P, Moody's ve Fitch tarafından Türkiye'nin derecelendirme notuna ilişkin yapılan duyuruların, devlet iç borçlanma senetlerinin (DiBS) gösterge niteliğindeki değerleri üzerindeki etkisi de olay analizi yöntemi ile incelenmiştir. Ancak, kurulan modellerin tamamında, gösterge niteliğindeki DiBS değerlerinin, olay öncesi ve sonrası dönemlerde istatistiki olarak anlamlı bir şekilde farklılaşmadığı tespit edilmiştir.

\section{KAYNAKLAR}

Abad, P. ve Robles, M. D. (2014), Credit Rating Agencies and Idiosyncratic Risk: Is There a Linkage? Evidence from The Spanish Market, International Review of Economics and Finance, 33, p.152-171.

Afik, Z., Feinstein, I. ve Galil, K. (2014), The (Un)Informative Value of Credit Rating Announcements in Small Markets, Journal of Financial Stability, 14, p.66-80.

Afonso, A., Gomes, P. ve Taamouti, A. (2014), Sovereign Credit Ratings, Market Volatility, and Financial Gains, Computational Statistics and Data Analysis, 76, p.20-33.

Afonso, A., Furceri, D., Gomes, P. (2012), Sovereign Credit Ratings and Financial Markets Linkages: Application to European Data, Journal of International Money and Finance, 31, p.606-638.

Altunışık, R., Coşkun, R., Bayraktaroğlu, S. ve Yıldırım, E. (2007), Sosyal Bilimlerde Araştırma Yöntemleri SPSS Uygulamalı, (5. Baskı) Sakarya: Sakarya Yayıncılık.

Bissoondoyal-Bheenick E. ve Brooks, R. (2014), The Credit Risk-Return Puzzle: Impact of Credit Rating Announcements in Australia and Japan, Pacific-Basin Finance Journal. http://dx.doi.org/10.1016/j.pacfin.2014.09.001.

Blau, B. M. ve Roseman, B. S. (2014), The Reaction of European Credit Default Swap Spreads to The U.S. Credit Rating Downgrade, International Review of Economics and Finance, 34, p.131-141.

Böninghausen, B. ve Zabel, M. (2015), Credit Ratings and Cross-Border Bond Market Spillovers, Journal of International Money and Finance, 53, p.115-136.

Büyüköztürk, Ş. (2012), Sosyal Bilimler İçin Veri Analizi El Kitabı, (16. Baskı) Ankara: Pegem Akademi.

Christopher, R., Kim, S. J. ve Wu, E. (2012), Do Sovereign Credit Ratings Influence Regional Stock and Bond Market Interdependencies in Emerging Countries?, Journal of International Financial Markets, Institutions and Money, 22, p.1070-1089.

Fatum, R. ve Hutchison, M. M. (2003), Is Sterilised Foreign Exchange Intervention Effective After All? An Evenet Study Approach, The Economic Journal. 113 (April), p.390-411.

Finnerty, J. D., Miller C. D. ve Chen R. R. (2013), The Impact of Credit Rating Announcements on Credit Default Swap Spreads, Journal of Banking \& Finance, 37, p.2011-2030.

Gürsakal, N. (2014), Çıkarımsal İstatistik Minitab-SPSS Uygulamalı, (6. Baskı) Bursa: Dora Yayınevi.

Henderson, G. V. (1990), Problems and Solutions in Conducting Event Studies, The Journal of Risk and Insurance, $57(2)$, p.282-306.

Hull, J., Predescu, M. ve White, A. (2004), The Relationship Between Credit Default Swap Spreads, Bond Yields, and Credit Rating Announcements, Journal of Banking \& Finance, 28, p.2789-2811. 
Ismailescu, I. ve Kazemi, H. (2010), The Reaction of Emerging Market Credit Default Swap Spreads to Sovereign Credit Rating Changes, Journal of Banking \& Finance, 34, p.2861-2873.

Kiff, J. ve Morrow, R. (2000), Credit Derivatives, Bank of Canada Review, Autumn, 3.

Lehnert, T. ve Neske, F. (2006), On The Relationship Between Credit Rating Announcements and Credit Default Swap Spreads for European Reference Entities, Journal of Credit Risk, 2(2), p.83-90.

Li, J., Shin, Y. S. ve Moore, W. T. (2006), Reactions of Japanese Markets to Changes in Credit Ratings by Global and Local Agencies, Journal of Banking \& Finance, 30, p.1007-1021.

MacKinlay, A. C. (1997), Event Studies in Economics and Finance, Journal of Economic Literature, 35(1), p.13-39.

Micu, M., Remolona, E. M. ve Wooldridge, P. D. (2004), The Price Impact of Rating Announcements: Evidence from The Credit Default Swap Market, BIS Ouarterly Review, p.55-66.

Micu, M., Remolona, E. ve Woolridge, P. (2006), The Price Impact of Rating Announcements: Which Announcements Matter?, BIS Working Papers, No: 207.

Norden, L. ve Weber, M. (2004), Informational Efficiency of Credit Default Swap and Stock Markets: The Impact of Credit Rating Announcements, Journal of Banking \& Finance, 28, p.2813-2843.

Standard \& Poor's (S\&P), Guide to Credit Rating Essentials. http://img.en25.com/Web/StandardandPoors/SP_CreditRatingsGuide.pdf, Son Erişim Tarihi: 22.06.2015.

Vu, H., Alsakka ve R., Gwilym, O. (2015), The Credit Signals That Matter Most for Sovereign Bond Spreads With Split Rating, Journal of International Money and Finance, 53, p.174-191.

Wang, J., Svec, J. ve Peat, M. (2014), The Information Content of Ratings: An Analysis of Australian Credit Default Swap Spreads. A Journal of Accounting, Finance and Business Studies. 50(1), p.56-75.

Wengner, A., Burghof, H. P. ve Schneider, J. (2015), The Impact of Credit Rating Announcements on Corporate CDS Markets-Are Intra-Industry Effects Observable?, Journal of Economics and Business, 78, p.79-91. 